\title{
Synthesis, physicochemical and optical properties of bis-thiosemicarbazone functionalized graphene oxide
}

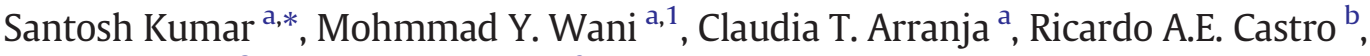 \\ José A. Paixão ${ }^{c}$, Abilio J.F.N. Sobral ${ }^{\mathrm{a}, *}$ \\ a Department of Chemistry, University of Coimbra, P-3004-535 Coimbra, Portugal \\ b CEF, Faculty of Pharmacy, University of Coimbra, P-3000-548 Coimbra, Portugal \\ ' Department of Physics, University of Coimbra, P-3004-516 Coimbra, Portugal
}

\section{A R T I C L E I N F O}

\section{Article history:}

Received 7 November 2016

Received in revised form 13 June 2017

Accepted 30 June 2017

Available online 1 July 2017

\section{Keywords:}

Graphene oxide

Bis-thiosemicarbazone

Characterization

Photoluminescence

\begin{abstract}
A B S T R A C T
Fluorescent materials are important for low-cost opto-electronic and biomedical sensor devices. In this study we present the synthesis and characterization of graphene modified with bis-thiosemicarbazone (BTS). This new material was characterized using Fourier transform infrared spectroscopy (FT-IR), Ultraviolet-visible (UV-Vis) and Raman spectroscopy techniques. Further evaluation by X-ray diffraction (XRD), thermo-gravimetric analysis (TGA), differential scanning calorimetry (DSC), scanning electron microscopy (SEM) and atomic-force microscopy (AFM) allowed us to fully characterize the morphology of the fabricated material. The average height of the BTSGO sheet is around $10 \mathrm{~nm}$. Optical properties of BTSGO evaluated by photoluminescence (PL) spectroscopy showed red shift at different excitation wavelength compared to graphene oxide or bisthiosemicarbazide alone. These results strongly suggest that BTSGO material could find potential applications in graphene based optoelectronic devices.
\end{abstract}

(c) 2017 Elsevier B.V. All rights reserved.

\section{Introduction}

In recent decades, graphene oxide has taken on an assortment of diverse roles, not only in optoelectronics but also as a material for nanoscale engineering. Graphene oxide, as a graphene-based inorganic carbon material, possesses many exceptional properties including nanoscale controllability and biocompatibility which merit attention for many potential applications. As a robust yet flexible material it provides many possibilities for facile modification and fabrication to produce other desired graphene based materials [1-7]. Recently, graphene has advanced its applications in biomedical and energy engineering [8-10]. Also the improvement of graphene based fluorescent sensors for evaluating biomolecules has received great attention due to in situ cellular imaging studies [11]. In a recent study of chitosan/ graphene oxide nanocomposite, it was found that the $\mathrm{pH}$ conditions affect the interaction between polymer and graphene oxide and hence the optical properties of the material [12]. Since graphene is a zero-bandgap semiconductor the possibility of observing luminescence is highly

\footnotetext{
* Corresponding authors.

E-mail addresses: santoshics@gmail.com, santosh.kumar@uc.pt (S. Kumar), asobral@ci.uc.pt (A.J.F.N. Sobral).

${ }^{1}$ Present address: Texas Therapeutics Institute, Brown Foundation Institute of Molecular Medicine, The University of Texas Health Science Center at Houston, 1881 East Road, Houston, 77,054, Texas, United States.
}

unlikely [13], and therefore, studies being conducted to increasing the band gap are important. An important strategy is to combine graphene oxide with some conjugated organic molecule to improve its optical properties.

Thiosemicarbazones constitute an interesting class of compounds with wide pharmacological versatility with anti-tumor, anti-cancer, anti-inflammatory, anti-protozoal, anti-bacterial and anti-viral activities [14-19]. Due to the presence of a conjugated system of double bonds and heteroatoms in the bis-thiosemicarbazone skeleton, it was speculated that the conjugation or fabrication of bis-thiosemicarbazone with graphene oxide could enhance the optical properties of graphene oxide. Despite the large amount of work done on graphene oxide, no literature precedents were found describing the fabrication and the study of the optical properties of bis-thiosemicarbazone-graphene oxide materials. We herein report the synthesis, physico-chemical and optical properties of BTSGO, a new material with potential to be applied as optical sensor or biosensor.

\section{Experimental Section}

\subsection{Materials and Reagents}

Graphite, $30 \% \mathrm{H}_{2} \mathrm{O}_{2}, \mathrm{KMnO}_{4}$, benzene-1,4-dicarbaldehyde and thiosemicarbazide were purchased from Sigma-Aldrich Co., (USA). 
Hydrochloric acid, $\mathrm{SOCl}_{2}$ and $\mathrm{H}_{2} \mathrm{SO}_{4}$ was obtained from Merck (Germany) and were used without further purification.

\subsection{Synthesis of Bis-thiosemicarbazone (BTS) (3)}

Bis-thiosemicarbazone (BTS) was synthesized as outlined in Scheme 1. Benzene-1,4-dicarbaldehyde (1) (1 mmol, $0.13 \mathrm{~g}$ ) was mixed with thiosemicarbazide (2) $(2 \mathrm{mmol}, 0.18 \mathrm{~g})$ in ethanol with few drops of $10 \% \mathrm{NaOH}$, and placed in reflux for $5 \mathrm{~h}$. Completion of the reaction was monitored by thin layer chromatography (TLC). After completion of the reaction, a pale yellow precipitate of BTS (3) was formed, which was filtered, dried and recrystallized in dichloromethane.

Yield 85\%; IR $\nu_{\max } \mathrm{cm}^{-1}$ : $3396(\mathrm{NH}), 3264,3191\left(\mathrm{NH}_{2}\right), 3010$ $(\mathrm{C}-\mathrm{H}), 1589(\mathrm{C}=\mathrm{C}), 1515(\mathrm{C}=\mathrm{N}), 1279(\mathrm{C}-\mathrm{N}), 1120(\mathrm{C}=\mathrm{S}) ;{ }^{1} \mathrm{H}$ NMR (DMSO-d $\left.d_{6}\right) \delta(\mathrm{ppm}): 8.30(2 \mathrm{H}, \mathrm{s},-\mathrm{NH}), 8.00(2 \mathrm{H}, \mathrm{s},-\mathrm{CH}=\mathrm{N})$, $7.80(\mathrm{~s}, 4 \mathrm{H}, \mathrm{Ar}), 3.35\left(\mathrm{~s}, 4 \mathrm{H}, \mathrm{NH}_{2}\right) ;{ }^{13} \mathrm{C}$ NMR $\left(\mathrm{DMSO}-d_{6}\right) \delta(\mathrm{ppm})$ : $177.91(\mathrm{C}=\mathrm{S}), 141.55(\mathrm{C}=\mathrm{N}), 135.30,127.42$; ESI-MS $m / z:\left[\mathrm{M}^{+}+1\right]$ 281.25, corresponding to the expected Mol. Formula $\mathrm{C}_{10} \mathrm{H}_{12} \mathrm{~N}_{6} \mathrm{~S}_{2}$.

\subsection{Synthesis of Graphene Oxide}

Graphene oxide (GO) was prepared by previous reported method of the oxidation of graphite using a modified Hummers method [12,20].
Natural graphite ( $3 \mathrm{~g}$ ) was taken in a $250 \mathrm{~mL}$ round bottom flask and added to cold concentrated sulfuric acid $(69 \mathrm{~mL})$, which was stirring in the ice-bath. Potassium permanganate $(9 \mathrm{~g})$ was poured in the round bottom flask under stirring in an ice-bath. After that time the mixture was stirred at $35^{\circ} \mathrm{C}$ for $2 \mathrm{~h}$, and then distilled water $(150 \mathrm{~mL})$ was added slowly for $15 \mathrm{~min}$ to the mixture and raised the temperature $\left(100{ }^{\circ} \mathrm{C}\right)$ it for another $15 \mathrm{~min}$. The mixture was added into the $400 \mathrm{~mL}$ of $30 \% \mathrm{H}_{2} \mathrm{O}_{2}$ aqueous solution. Then, the product was filtered and washed with $10 \%$ aqueous hydrochloric acid solution and finally powder was washed with distilled water. The brownish yellow powder obtained was dried under reduced pressure for $24 \mathrm{~h}$.

2.4. Fabrication of Graphene Oxide-Bisthiosemicarbazone (BTSGO) Material (5)

For the fabrication of BTSGO, initially the carboxylic acid groups of $\mathrm{GO}$ were acylated with $\mathrm{SOCl}_{2}$ in a $100 \mathrm{~mL}$ round bottom flask, using $200 \mathrm{mg}$ of graphene oxide in $1 \mathrm{~mL}$ of DMF in $\mathrm{N}_{2}$ atmosphere, under reflux. Solvent was removed by distillation, the crude product was washed with THF, centrifused and dried under vacuum. The obtained acylated product (4) was further treated with BTS in DMF to afford the desired material. The BTSGO was prepared in the following way: $87 \mathrm{mg}$ of $\mathrm{GOCl}$ (4) was dissolved into $10 \mathrm{~mL}$ of DMF and $87 \mathrm{mg}$ of BTS

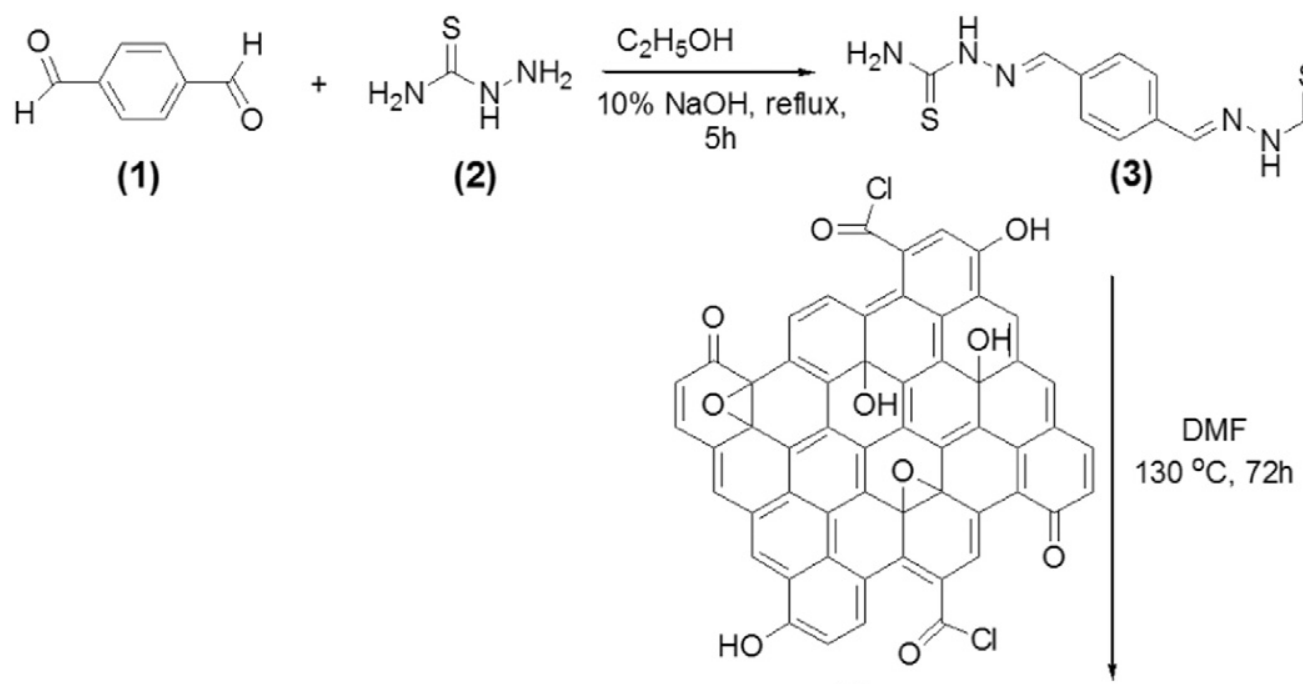

(4)

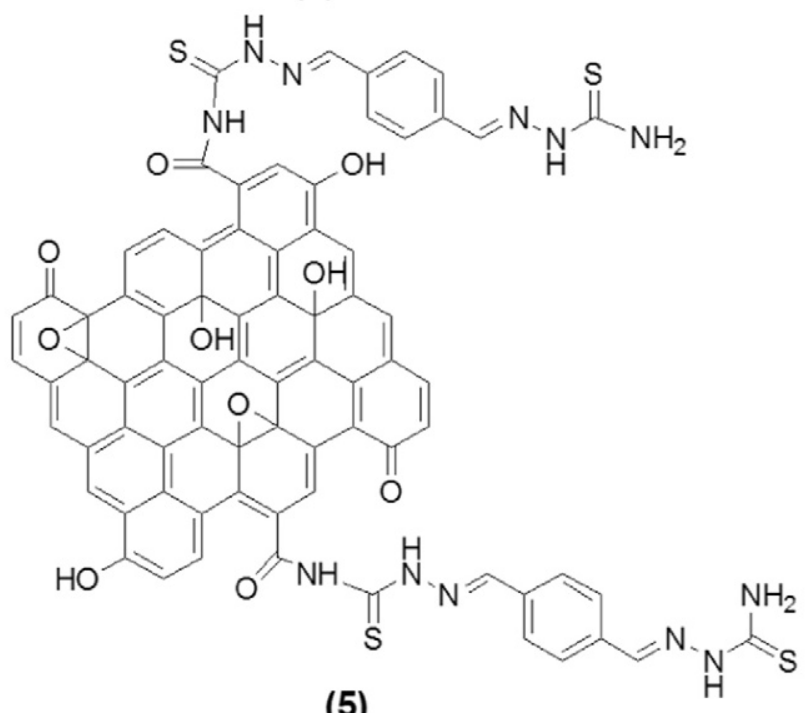

(5) 
was allowed to react with the above solution at $130^{\circ} \mathrm{C}$ for $72 \mathrm{~h}$ under an argon atmosphere. After the completion of the reaction, the solution was cooled to room temperature and the contents were poured into ethanol to precipitate the product. The product was obtained by filtration. The excess of BTS and other impurities were removed through washing with ethanol and the eluted was monitored by UV spectroscopy and TLC to ensure that no BTS existed in the final washing.

\subsection{Characterization}

Fourier transform infrared (FT-IR) spectra of the materials were recorded on a Thermo Nicolet IR300 FT-IR spectrometer with attenuated total reflectance (ATR) plate Smart Orbit Diamond, resolution $2 \mathrm{~cm}^{-1}$, 64 scans. The Raman spectra were obtained by a Raman spectroscopy, Nicolet DXR Smart Raman, laser $514 \mathrm{~nm}$ (Ar-ion laser), power = $0.5 \mathrm{~mW}$. The Powder X-ray diffraction (XRD) patterns were recorded using a Bruker D8 Advance diffractometer, equipped with a $3 \mathrm{~kW}$ generator, using Ni-filtered $\mathrm{Cu} \mathrm{K \alpha}$ radiation $(\lambda=0.15418 \mathrm{~nm})$ and a LYNXEYE detector. Data were collected in Bragg-Brentano geometry with a fixed $0.3^{\circ}$ divergence slit. Thermogravimetry studies were performed in a Perkin-Elmer STA 6000 with a cooling unit providing a base temperature of $15^{\circ} \mathrm{C}$, and a dynamic nitrogen atmosphere flowing at $20 \mathrm{~mL} \cdot \mathrm{min}^{-1}$. Temperature calibration was performed with indium (Perkin-Elmer, $\mathrm{x}=99.99 \%, T_{\text {fus }}=156.60{ }^{\circ} \mathrm{C}$ ) and zinc (Perkin-Elmer, $\mathrm{x}=99.99 \%, T_{\text {fus }}=419.53{ }^{\circ} \mathrm{C}$ ). Samples were heated from $25{ }^{\circ} \mathrm{C}$ to $800{ }^{\circ} \mathrm{C}$ at rate of $20^{\circ} \mathrm{C} \mathrm{min}{ }^{-1}$ in alumina crucibles. Scanning electron microscope (SEM) images were taken with a Tescan Vega3 SB scanning electron microscope. Images were collected using a secondary electron detector. AFM images were obtained at ambient conditions using a NTEGRA Prima NT-MDT instrument in semi contact mode. A NSG30 probe with a resonance frequency around $250 \mathrm{kHz}$ was used. UV-visible absorption spectra were measured on an Agilent 8453 spectrophotometer (USA). ${ }^{1} \mathrm{H}$ NMR and ${ }^{13} \mathrm{C}$ NMR spectra were recorded on Bruker AVANCE 300 spectrometer using DMSO- $d_{6}$ as solvent with TMS as internal standard. Splitting patterns are designated as follows; s, singlet; d, doublet; dd, doublet of doublets; t, triplet; $m$, multiplet. Chemical shift values are given in ppm. ESI-MS was recorded on a Micromass Quattro II triple quadrupole mass spectrometer. Fluorescence spectra were obtained on a Horiba-Jobin-Yvon SPEX Fluorolog FL322.

\section{Results and Discussion}

\subsection{Physico-chemical Characterization}

Characteristic IR bands provide significant indications for the formation of BTS. The absence of a band at/or around $2665 \mathrm{~cm}^{-1}$ due to $-\mathrm{C}=\mathrm{O}$ of benzene-1,4-dicarbaldehyde and the appearance of characteristic bands around at $1515 \mathrm{~cm}^{-1}$ region due to $\nu(\mathrm{C}=\mathrm{N})$ stretch

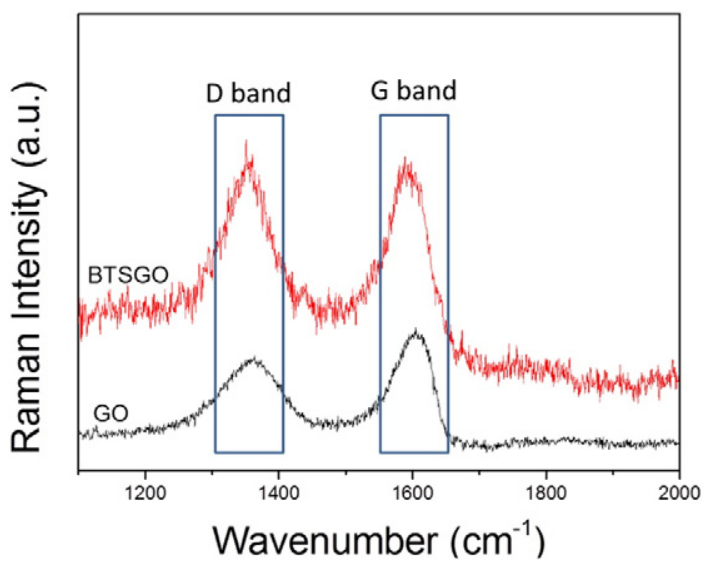

Fig. 1. Raman spectra of GO and BTSGO.

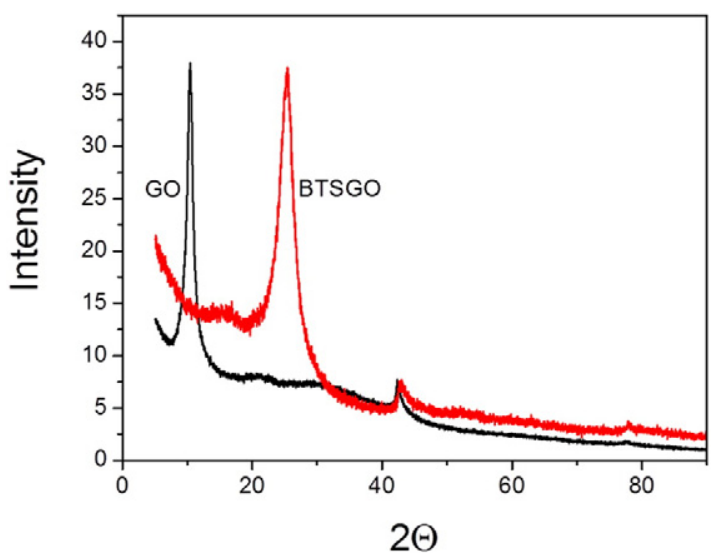

Fig. 2. XRD pattern of GO and BTSGO.

confirmed the formation of the BTS. Thiosemicarbazones may exhibit thione-thiol tautomerism, since they have a thione group $(\mathrm{C}=\mathrm{S})$ and proton adjacent to the thione group. It has been stated that the thione group $(\mathrm{C}=\mathrm{S})$ is relatively unstable in the monomeric form and tends to turn into a stable $\mathrm{C}-\mathrm{S}$ single bond by tautomerism, if there is at least one hydrogen atom adjacent to the $\mathrm{C}=\mathrm{S}$ bond. However, BTS showed intense, strong bands in the region 1081 and $805 \mathrm{~cm}^{-1}$ due to $\nu(\mathrm{C}=\mathrm{S})$ stretch [21] and no band near $2570 \mathrm{~cm}^{-1}$ due to $\nu(\mathrm{C}-\mathrm{SH})$, suggesting that this compound remains in the thione form. The FT-IR spectra of graphene oxide showed absorption band at $1724 \mathrm{~cm}^{-1}$, characteristic of $C=0$ stretching. The absorption peak at $1620 \mathrm{~cm}^{-1}$ is either assigned to the deformation of the $\mathrm{OH}$ band of the water absorbed by graphene oxide, or stretching of the aromatic $\mathrm{C}=\mathrm{C}$ bond and $846 \mathrm{~cm}^{-1}$ to the characteristic absorption peak of epoxy groups. The FTIR spectra of BTSGO showed vibrational bands different from the corresponding materials, signifying some sort of interaction between GO and BTS as is evident from the distortion of amide bands of BTS in BTSGO.

Raman is supported to analyse changes in electronic structure due to $\mathrm{C}-\mathrm{C}$ bonds and defects. Raman spectra of graphene oxide and BTSGO displayed two prominent peaks at about $1352 \mathrm{~cm}^{-1}$ (D band) and about $1590 \mathrm{~cm}^{-1}$ (G band), as shown in Fig. 1. However, the band intensity ratio $\left(r=\mathrm{I}_{\mathrm{D}} / \mathrm{I}_{\mathrm{G}}\right)$ for BTSGO $(r=1.00)$ shows an enhanced value compared to that for graphene oxide $(r=0.84)$. BTSGO shows higher defect density compared to GO. The defects sites can be anticipated to play a positive role in contributing to the enhancement of photoluminescence.

$\mathrm{X}$-ray diffractive region of pristine graphene oxide is observed at $2 \Theta=11^{\circ}[12]$. Comparing the BTSGO diffractogram with that of GO we can see that the characteristic peak of GO is no longer present

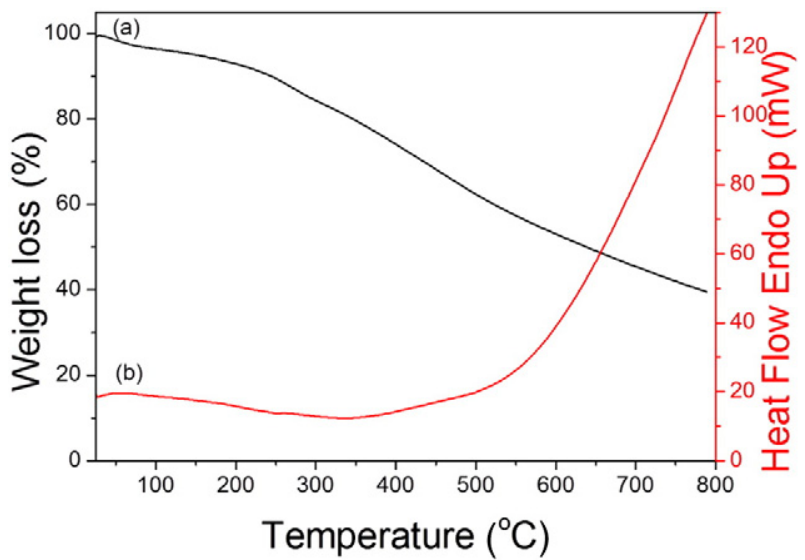

Fig. 3. TG/DSC curve of BTSGO. 

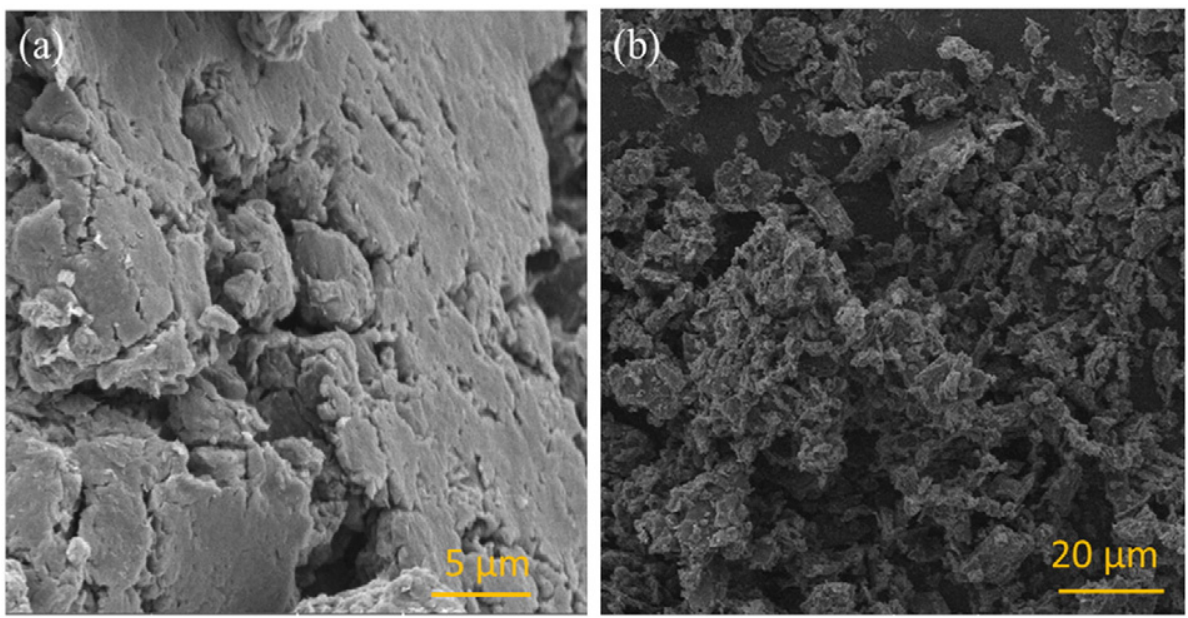

Fig. 4. SEM image of GO (a) and BTSGO (b).

and an intense peak is now found at a larger Bragg angle. The increase in $d$-spacing is due to the intercalation of amide functional groups in between graphene layers. BTSGO showed an intense sharp peak at around $2 \Theta=25.45^{\circ}$ and smaller peak at $42.79^{\circ}$ (Fig. 2.). This shows the incorporation of BTS into the graphene oxide matrix.

\subsection{Thermal Analysis}

The thermal stability of the BTSGO was studied by thermogravimetric analysis as shown in Fig. 3a. The initial weight loss of BTSGO ca. 6\% at around $45^{\circ} \mathrm{C}$, was due to evaporation of water, whereas the second stage of weight loss at $260{ }^{\circ} \mathrm{C}$ is due to the degradation of the BTS. In the corresponding DSC signal (Fig. 3b) it is only observable a small changes for the dehydration and another small endothermic event for the degradation. The mass loss of GO is ca. $7 \%$ at around $80{ }^{\circ} \mathrm{C}$, which can be assigned to the removal of $\mathrm{H}_{2} \mathrm{O}$ molecules adsorbed inside the GO structure (not shown in the Fig.3). A mass loss of ca. 55\% occurring around $170{ }^{\circ} \mathrm{C}$ is ascribed to the pyrolysis of the labile oxygen-containing groups in the forms of $\mathrm{CO}, \mathrm{CO}_{2}$ and $\mathrm{H}_{2} \mathrm{O}$ [22]. The change in the degradation temperature of BTSGO to a higher value shows that this material has higher thermal stability compared to GO.
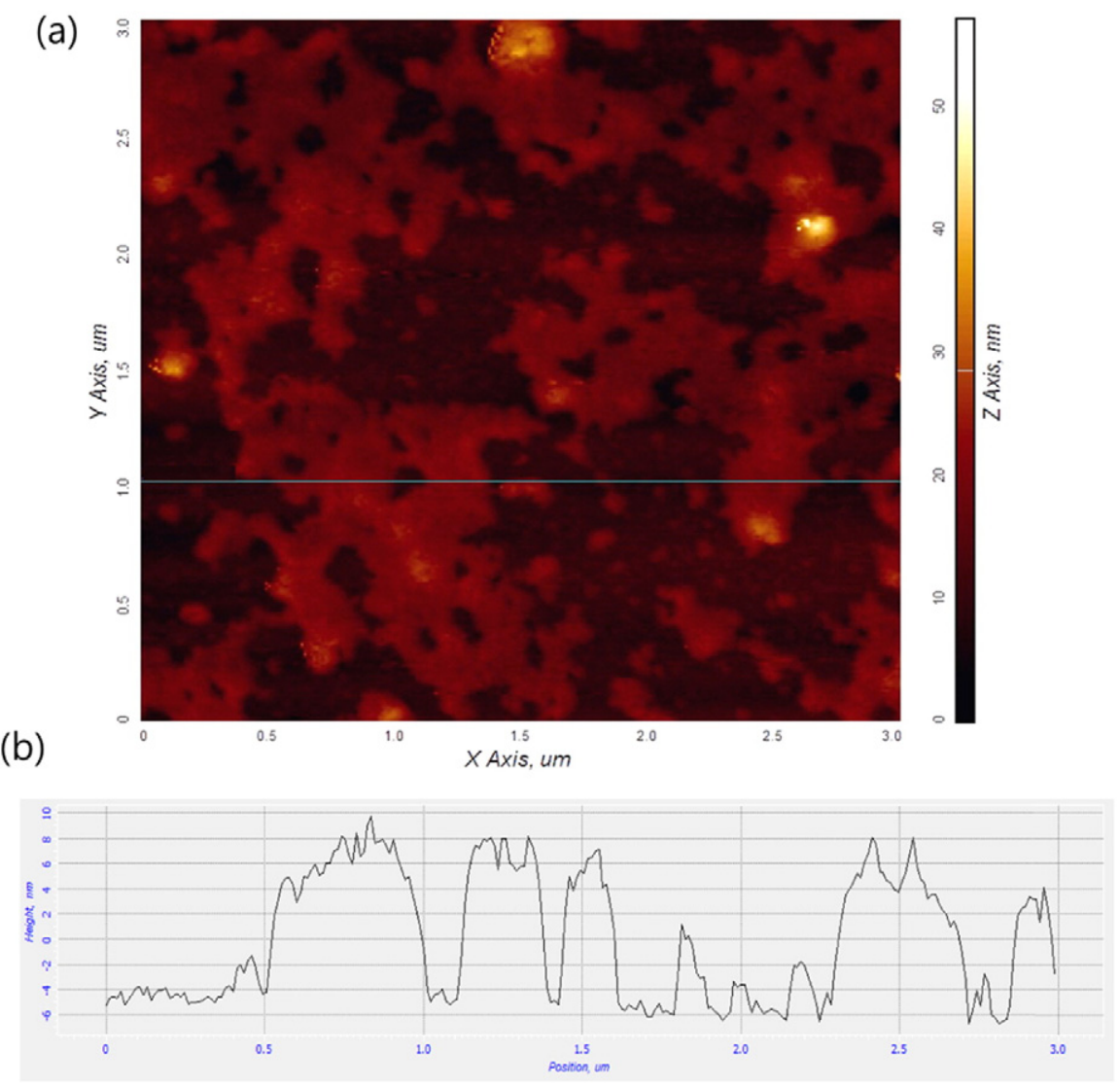

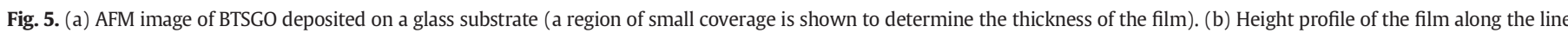
depicted in a). 


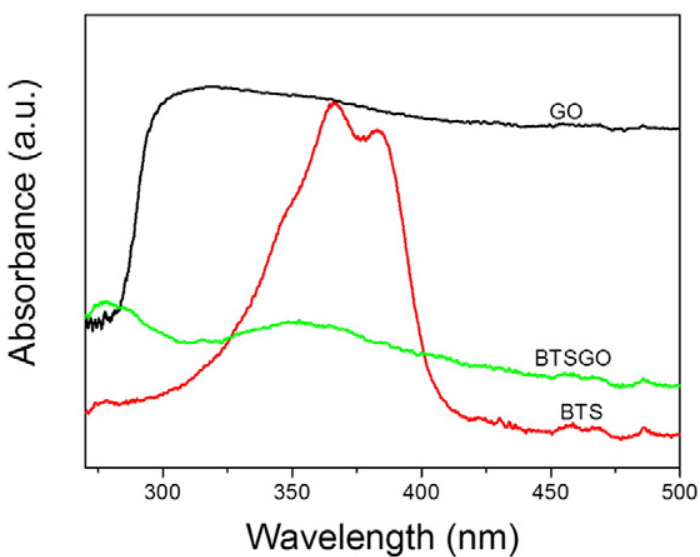

Fig. 6. UV-visible spectra of GO, BTS and BTSGO.

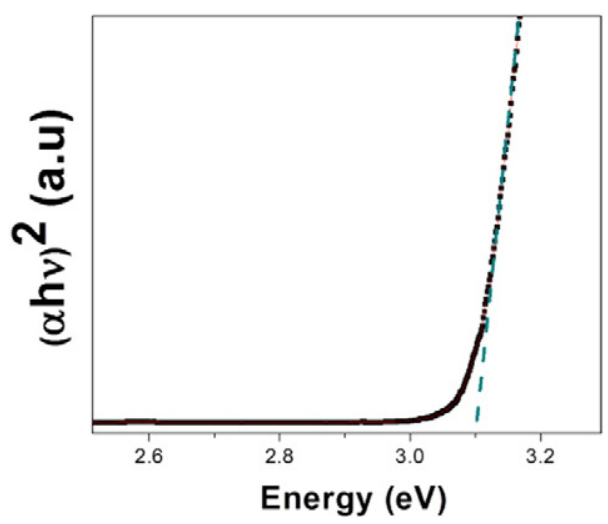

Fig. 7. Plot of $(\alpha h v)^{2}$ against Energy $(h \nu)$ for BTSGO.

\subsection{Surface Morphology}

The morphology of the GO (Fig. 4a) and BTSGO (Fig. 4b) was investigated by scanning electron microscopy (SEM). The images of BTSGO showed a porous structure, confirming a strong effect of the BTS over the pristine GO. The AFM images shown in Fig. 5a and b indicate that BTSGO has an average thickness of around $10 \mathrm{~nm}$ indicating that BTSGO lies as a mixture of single and double-layered sheets. AFM image also reveals that the structure of BTSGO is formed as a result of the fabrication of BTS molecules on the GO surface, which gives an irregular texture to the BTSGO material, in the form of sheets.

(a)

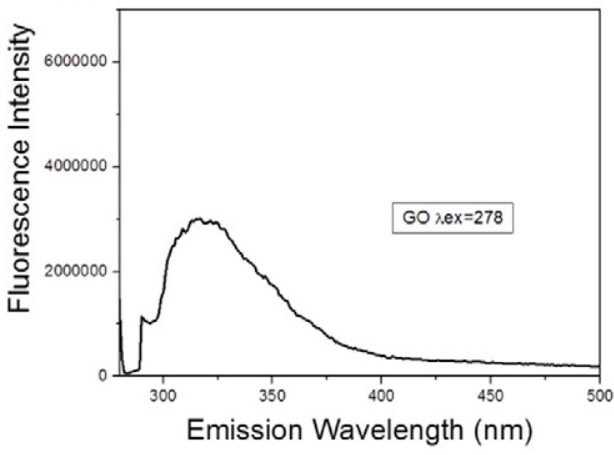

\subsection{UV-Vis Absorption Spectra}

The UV-Vis spectra of graphene oxide, BTS and BTSGO in DMF solution are shown in Fig. 6. The graphene oxide has a characteristic shoulder around at $310-320 \mathrm{~nm}$ observed due to the $n-\pi^{*}$ transition of $C=0$ [23]. BTS has two characteristic peaks at 366 and $383 \mathrm{~nm}$. A characteristic absorption peak was observed in BTSGO at $360 \mathrm{~nm}$ due to $\pi-\pi^{*}$ transition. GO is unexplored in the field of optical application due to its poor optical property generated from zero band gap characteristics, however we observed that BTSGO has an optical energy band gap of $3.1 \mathrm{eV}$, a feature desirable for a graphene based material for use in optoelectronic devices [24] (Fig. 7).

\subsection{Photoluminescence (PL) Study}

The photoluminescence studies of graphene oxide and BTSGO were performed to understand its emission properties as shown in Fig. 8. The graphene oxide had emission spectrum $\left(\lambda_{\mathrm{em}}\right)$ peak at $320 \mathrm{~nm}$ at excitation wavelength of $278 \mathrm{~nm}$ (Fig. 8a). The PL spectrum of BTSGO showed emission maximum $\left(\lambda_{\mathrm{em}}\right)$ peak at $440 \mathrm{~nm}$ under excitation wavelength of $278 \mathrm{~nm}$, which explains red-shifted emission maxima due to bandgap transitions corresponding to conjugated $\pi$-domains and the other with more complex origins that are more or less associated with defects in the graphene structure [25-26]. BTS itself did not show any photoluminescent properties but the presence of GO and BTS together in BTSGO resulted in photoluminescence, which could be due to the synergetic effect of chemical and physical properties of both BTS and GO. BTSGO is highly dispersible in DMF and emits light in the visible when stimulated with different excitation wavelengths. We have observed, the photoluminescence peak of the BTSGO at around $440 \mathrm{~nm}$ when the excitation wavelength changed from $278 \mathrm{~nm}$ to $320 \mathrm{~nm}$ (as shown in Fig. 8b), no PL peak shifting but a dramatic increase in photoluminescence intensity. The similar phenomenon is reported previously different from the general excitation dependent PL emissions, in which the PL peaks shift to longer wavelengths upon an increase in the excitation wavelengths [27-30]. Zhang et al. have reported opposite phenomenon, the intensity of the PL increased to the maximum then decreased on excited wavelengths ranging from 340 to $410 \mathrm{~nm}$ in the graphene quantum dots [31]. Xu et al. have also observed the photoluminescence of fabricated nitrogen-doped graphene quantum dot at different excitation wavelengths [32].

\section{Conclusions}

The fascinating properties of graphene oxide derivatives such as functionalizable surfaces, strong UV absorption and photoluminescence ability make them one of the most promising materials for biosensors. We fabricated a new graphene based material and characterized it

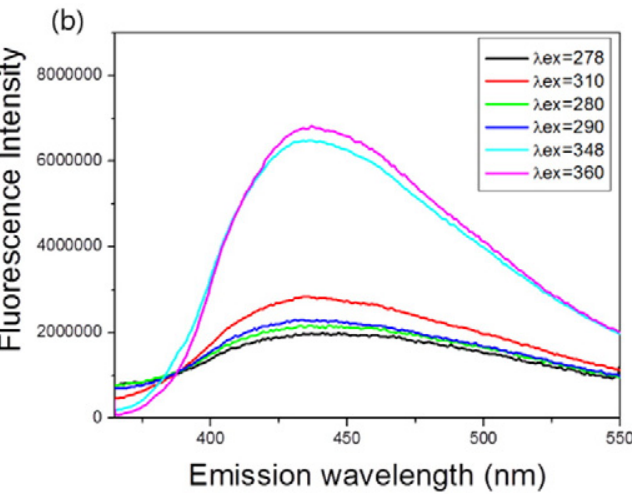

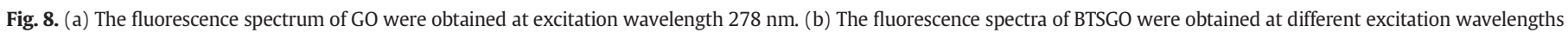
ranging from 278 to $360 \mathrm{~nm}$. 
using UV-Vis, FT-IR, Raman and X-ray diffractometry analysis. The morphological study indicates surface of the fabricated material. The thermal studies showed that this material is thermally more stable than graphene oxide. The photoluminescence spectra showed optical properties. Our findings points to the possibility of BTSGO be used as a tool for biomedical applications, where a strong photoluminescent graphene based material can be used.

\section{Acknowledgements}

Thanks are due to the European Regional Development Fund-QRENCOMPETE for funding the project PTDC/AAC-CLI/118092/2010 coordinated by Prof. Abilio Sobral, and Centro de Quimica by PEst-C/QUI/ UI0313/2014) and FCT, Portugal for his grant S. Kumar (SFRH/BPD/ 86507/2012), M.Y. Wani (SFRH/BPD/86581/2012) and Access to TAILUC facility funded under QREN-Mais Centro Project ICT/2009/02/012/ 1890 is gratefully acknowledged.

\section{References}

[1] Z. Gan, H. Xu, Y. Hao, Nano 8 (2016) 7794.

[2] X. Michalet, F.F. Pinaud, L.A. Bentolila, J.M. Tsay, S. Doose, J.J. Li, G. Sundaresan, A.M. Wu, S.S. Gambhir, S. Weiss, Science 307 (2005) 538.

[3] C. Chung, Y. Kim, D. Shin, S.R. Ryoo, B.H. Hong, D. Min, Acc. Chem. Res. 46 (2013) 2211.

[4] Y.L. Liu, X.Y. Wang, J.Q. Xu, C. Xiao, Y.H. Liu, X.W. Zhang, J.T. Liu, W.H. Huang, Chem. Sci. 6 (2015) 1853.

[5] (a) H. Jang, J. Lee, D.H. Min, J. Mater. Chem. B 2 (2014) 2452;

(b) J. Chatopadhyay, R. Srivastava, P.K. Srivastava, Int. J. Electrochem. Sci. 8 (2013) 3740.

[6] A. Ambrosi, C.K. Chua, N.M. Latiff, A.H. Loo, C.H.A. Wong, A.Y.S. Eng, A. Bonanni, M. Pumera, Chem. Soc. Rev. 45 (2016) 2458-2493.

[7] C.V. Pham, M. Krueger, M. Eck, S. Weber, E. Erdem, Appl. Phys. Lett. 104 (2014) 132102.
[8] (a) X. Zou, L. Zhang, Z. Wang, Y. Luo, J. Am. Chem. Soc. 138 (2016) 2064; (b) Y. Zhang, Q. Tang, B. He, P. Yang, J. Mater. Chem. A 4 (2016) 13235.

[9] S. Kumar, M.Y. Wani, J. Koh, J. Gil, A.J.F.N. Sobral, J. Environ. Sci. (2017) http://dx.doi. org/10.1016/j.jes.2017.04.013.

[10] P.K. Dutta, R. Srivastava, J. Dutta, Adv. Polym. Sci. 254 (2013) 1.

[11] L. Zhang, S.J. Xiao, L.L. Zheng, Y.F. Li, C.Z. Huang, J. Mater. Chem. B 2 (2014) 8558.

[12] S. Kumar, J. Koh, Int. J. Biol. Macromol. 70 (2014) 559.

[13] G. Eda, Y. Lin, C. Mattevi, H. Yamaguchi, H.A. Chen, I. Chen, C.W. Chen, M. Chhowalla, Adv. Mater. 22 (2010) 505.

[14] H. Beraldo, D. Gambino, Mini-Rev. Med. Chem. 4 (2004) 31.

[15] D. Palanimuthu, S.V. Shinde, K. Somasundaram, A.G. Samuelson, J. Med. Chem. 56 (2013) 722.

[16] B. Ma, B.C. Goh, E.H. Tan, K.C. Lam, R. Soo, S.S. Leong, L.Z. Wang, F. Mo, A.T.C. Chan, B. Zee, T. Mok, Investig. New Drugs 26 (2008) 169.

[17] H.B. Shawish, W.Y. Wong Y.L. Wong S.W. Loh, C.Y. Looi, P. Hassandarvish, A.Y. Phan, W.F. Wong, H. Wang, I.C. Paterson, C.K. Ea, M.R. Mustafa, M.J. Maah, PLoS One 9 (2014), e100933.

[18] R.A. Finch, M.C. Liu, A.H. Cory, J.G. Cory, A.C. Sartorelli, Adv. Enzym. Regul. 39 (1999) 3.

[19] W. Antholine, J. Knight, H. Whelan, D.H. Petering, Mol. Pharmacol. 13 (1977) 89.

[20] (a) W.S. Hummers, R.E. Offeman, J. Am. Chem. Soc. 80 (1958) 1339; (b) C. Hou, Q Zhang M. Zhu, Y. Li, H. Wang Carbon 49 (2011) 47.

[21] D.M. Wiles, B.A. Gingkas, F. Suprlnch, Can. J. Chem. 45 (1907) 469.

[22] J. Shen, Y. Hu, M. Shi, X. Lu, C. Qin, C. Li, M. Ye, Chem. Mater. 21 (2009) 3514.

[23] Z. Luo, Y. Lu, L.A. Somers, A.T.C. Johnson, J. Am. Chem. Soc. 131 (2009) 898.

[24] Y. Shen, S. Yang, P. Zhou, Q. Sun, P. Wang, L. Wan, J. Li, L. Chen, X. Wang, S. Ding, D.W. Zhang, Carbon 62 (2013) 157.

[25] L. Cao, M.J. Meziani, S. Sahu, Y.P. Sun, Acc. Chem. Res. 46 (2013) 171.

[26] C.V. Pham, S. Repp, R. Thomann, M. Krueger, S. Weberc, E. Erdem, Nano 8 (2016) 9682.

[27] S.K. Cushing, M. Li, F. Huang, N. Wu, ACS Nano 8 (2014) 1002.

[28] Q. Mei, K. Zhang, G. Guan, B. Liu, S. Wang, Z. Zhang, Chem. Commun. 46 (2010) 7319.

[29] S. Kumar, P. Garg, S. Pandey, M. Kumari, S. Hoon, R. Kapavarapu, P.H. Choung, A.J.F.N. Sobral, J.H. Chung, J. Mater. Chem. B 3 (2015) 3465.

[30] P.C. Hsu, P. Chen, C.M. Ou, H.Y. Chang, H.T. Chang, J. Mater. Chem. B 1 (2013) 1774

[31] M. Zhang, L. Bai, W. Shang, W. Xie, H. Ma, Y. Fu, D. Fang, H. Sun, L. Fan, M. Han, C. Liu S. Yang, J. Mater. Chem. 22 (2012) 7461.

[32] H. Xu, S. Zhou, L. Xiao, H. Wang, S. Li, Q. Yuan, J. Mater. Chem. C 3 (2015) 291. 